\title{
POLÍTICAS PÚBLICAS Y GOBIERNO PÚBLICO EN MEDELLÍN. ESTRATEGIAS DE CONSOLIDACIÓN DEL DERECHO PÚBLICO CON PERSPECTIVA TERRITORIAL, 2008-2009'
}

Recibido: junio 15. Aprobado: julio 6

\author{
Ramiro Vélez Rivera" \\ Director de la investigación"'.
}

\section{RESUMEN}

La investigación desarrollada está enfocada a identificar la lógica interna de funcionamiento del gobierno institucional que en Medellín ha propiciado la aplicación de políticas gubernamentales que asumen el territorio y el poder público como estrategias de articulación formal del Estado municipal y la ciudadanía; igualmente exploraremos la estructura y efectos de la política pública local, con carácter territorial y organizativo, que legitima gobiernos públicos en Medellín, responsables de nuevas expresiones territoriales, sustentadas en desarrollo social y local, apropiado para comprender micropolíticas y acciones públicas locales relacionadas con organizaciones sociales que activan sistemas de decisión vinculados con agendas públicas locales.

PALABRAS CLAVE: políticas públicas, derecho público, gobierno público, agendas públicas, territorio.

\section{PUBLIC POLICIES AND PUBLIC GOVERNMENT IN MEDELLIN. STRATEGIES OF CONSOLIDATION OF PUBLIC RIGHTS WITH TERRITORIAL PERSPECTIVE, 2008-2009}

ABSTRACT: The investigation being developed here, is focused on identifying the internal logic of institutional government operation which in Medellin has been a great factor for the application of governmental policies assumed by the territory and the public power as strategies of formal articulation of the municipal State and the citizens; also we will explore the structure and effects of the local public policy with territorial and organizational characters that legitimate public governments in Medellin responsible for new territorial expressions supported by

I El presente artículo es un avance de la investigación titulada con el mismo nombre, adelantada por el grupo de investigación Ratio Juris, de la Facultad de Derecho de la Universidad Autónoma Latinoamericana, enmarcada en el proyecto de investigación Derecho Público y Políticas Públicas.

II Magíster en Ciencia Política de la Universidad de Antioquia. Investigador Principal. Docente de la Facultad de Derecho, Universidad Autónoma Latinoamericana.

III El semillero de investigación está conformado por los estudiantes de $5^{\circ}$ año de la Facultad de Derecho Diana Cristina Orrego Ortiz, Paula Andrea López Suárez, Isabel Cristina Uribe Martínez, Xiomara Castro García, Andrés David Puello Calle, Paula Andrea Pérez Alzate, Andrés Jiménez Benavides, Linet María Dávila Puerta, Ángel Jarol Conde, Katherine Franco Hincapié, Sindy Rubiano Calambás, Ana María Giraldo Henao y Astrid Vanessa Jiménez Zapata. 
appropriate social and local development in order to understand micro policies and local public actions related to social organizations that activate decision systems tied to local public agendas.

KEY WORDS: public policies, public rights, public government, public agendas, territory.

POLÍTICAS PÚBLICAS Y GOBIERNO PÚBLICO EN MEDELLÍN. ESTRATEGIAS DE CONSOLIDACIÓN DEL DERECHO PÚBLICO CON PERSPECTIVA TERRITORIAL, 2008-2009.

La institucionalidad municipal y la administración pública formal han constituido los referentes clásicos de la esfera pública de Medellín en la perspectiva de desarrollar los imperativos del derecho público, enfocados a regular la relación del Estado y la ciudadanía, al control de las instituciones politicas y a la garantía de la unidad jurídica en temas de participación e intervención de la ciudadanía en asuntos públicos. La institucionalidad de Medellín ha consagrado importantes décadas al fortalecimiento de la cultura jurídica y política, sustentada en la centralización gubernamental y en diseños administrativos, orientados al ordenamiento territorial con sentido jurídico $\mathrm{y}$ formal.

En este panorama observamos la importancia histórica de la figura de la alcaldía municipal, que en la ciudad concentra el poder político para garantizar el orden interno, el desarrollo

de los objetivos de la administración pública, el control territorial de la ciudad, los mecanismos de relación de la ciudadanía con la participación social y la aplicación de las leyes que garanticen la unidad del Estado colombiano. En efecto, la alcaldía municipal en Medellín ha representado el centro de interés político, jurídico y administrativo del Estado municipal, con el objetivo de garantizar la articulación del nivel municipal del Estado colombiano con los principios de descentralización y unidad territorial, articulación sustentada en la actuación de tres factores estratégicos en la esfera pública de Medellín: el gobierno institucional las políticas gubernamentales y el ordenamiento territorial.
El gobierno institucional ha representado el escenario político-administrativo para que las alcaldías municipales de Medellín ejerzan el poder en la perspectiva de garantizar la unidad constitucional del Estado municipal y en la perspectiva de regularizar las mediaciones políticas y sociales de la administración pública municipal con la ciudadanía. El gobierno institucional constituye el mecanismo de jerarquizacio ciudad en expertos planificadores de la administración y en sectores ciudadanos que establecen relaciones de asistencialismo con la alcaldía. Por tanto, el gobierno institucional de Medellín refleja la cosmovisión política y administrativa que me diante el plan de des se aplica en la ciudad para sustentar la superposición del alcalde sobre la ciudadanía.

Las políticas gubernamentales constituyen otro factor de articulación de la alcaldía de Medellín con la unidad constitucional del Estado municipal, considerando que el diseño e implementación de programas con perspectiva local en la ciudad, es la herramienta apropiada para cumplir con los objetivos del plan de desarrollo y para garantizar la transición de la administración pública a en consecuencia, las políticas gubernamentales del nivel municipal ponen en contacto la cosmovisión del desarrollo de la alcaldía con las iniciativas participativas de la ciudadanía as políticas de gobierno actúan como enlace de la concepción formal de lo público con las prácticas políticas clásicas de la ciudadanía.

El ordenamiento territorial de Medellín, explicado a partir de la Ley 388 de 1997, y de la planeación institucional del territorio, partiendo de la lógica distributiva del poder territorial promovida por tes y sectores privados de Medellín, constituye un factor estratégico para comprender la articulación del Estado y la figura de la alcaldía municipal de Medellín. En efecto, en la ciudad han dominado e funcionalismo jurídico y administrativo en el tema del ordenamiento territorial, considerando que en Medellín el contacto de la ciudadanía con el territorio se restringe al lenguaje institucional de zonas, corregimientos y comunas; el territorio en la ciudad cumple con la doble función de diagrama administrativo para el desarrollo de proyectos de ciudad y espacio público para la garantía del orden y la seguridad institucional.

El gobierno institucional, las políticas gubernamentales y el ordenamiento territorial en Medellín, constituyen factores estratégicos para la consolidación del Estado municipal y de la alcaldía municipal como factor de poder político generador de confianza institucional para la ciudadaní de Medellín. Los factores indicados constituyen I estructura política de la cosmovisión instituciona de Medellín que representa críticamente el panorama de interés de la investigación: Políticas públicas y gobierno público en Medellín, estrategias de consolidación del derecho público con perspectiva territorial, 2008-2009

En efecto, esta investigación está enfocada a iden tificar y caracterizar los contenidos del gobierno institucional que han restringido el ascenso de políticas públicas en Medellín, considerando el enfoque local, territorial y organizativo. La investigación está diseñada para postular los argumento apropiados que indiquen el ascenso del gobierno público y las políticas públicas en Medellín, al considerar dinámicas territoriales correspondientes a factores de poder local y actores ciudadanos consolidados en organizaciones sociales facilitadoras de poder local en Medellín, vinculadas por políticas públicas, expresadas en sistemas de decisión local.

La investigación Políticas públicas y gobierno público en Medellín, estrategias de consolidación del derecho público con perspectiva territorial 2008-2009, se enfoca a indagar por el papel que cumplen el sector público y sus burocracias, en la consolidación del gobierno institucional del nivel municipal en Medellín.

Simultáneamente, exploraremos en las lógicas de poder local que relacionan el gobierno con políticas públicas locales en la ciudad, considerando las innovaciones políticas propiciadas por la articula ción de las agendas públicas a los sistemas de de cisión político-administrativos, con perspectiva de territorio; factor que permitirá multiplicar la capacidad de gobierno de las organizaciones sociales, sus discursos y políticas asociadas a la capacidad de acción pública local en Medellín.

Esta investigación contrastará la cosmovisión clásica del gobierno institucional y los ámbitos recientes de política pública local que surgen asociados al gobierno público y agendas públicas locales. El espacio analítico propiciado por este contraste, requiere explorar en la nomenclatura de la política pública y los públicos-organizativos y en la política pública vinculada con el desarrollo social y local.

\section{LA POLITICA PÚBLICA COMO ESTRATEGIA PARA} RECTIFICAR LO PÚBLICO.

Una política pública es una acción pública de carácter local que genera capacidad de gobierno en el actor social mediante la incorporación de sistemas de decisión que transforman territorial y socialmente una situación crítica en una alternativa de fortalecimiento de lo público.

Las políticas públicas están enfocadas a modela estrategias sociales y gubernamentales que revean la capacidad de asociación de las comunidades para deliberar sobre asuntos de interés público. En efecto, la política pública inclina sus intereses a sistemas de decisión que demuestran capacidad de gobierno en situaciones específicas en las que es evidente la distancia entre la formalidad estatal y la burocratización gubernamental; por tanto, la política pública pone en escena lo público y resta importancia al clásico debate propiciado por el bi- 
nomio Estado-sociedad civil, considerando que lo público ahora está tejido por actores locales y organizativos que han superado la órbita de los fines distributivos para interactuar con la esfera de los intereses y la pragmática de lo público.

La política pública, sus analistas y operadores se sitúan a finales de la década de los noventa, período característico del debate global-local que facilitó la separación de los fines jurídicos y las dinámicas prácticas en todas las sociedades del planeta. Para el caso de Latinoamérica y Colombia la relación indicada permitió reformas constitucionales $y$ reformas culturales concretas que han justificado el ascenso a la vida pública de actores sociales locales, dispuestos estratégicamente en el orden municipal colombiano con el propósito de asociarse para resolver problemáticas concretas de lo público. En efecto, las políticas públicas se inclinan a materializar estrategias de organizaciones sociales que ejercen gobierno local sobre asuntos prácticos de lo público, lo que permite indicar que la política pública logra visualizar tres tipos de públicos en la sociedad colombiana.

La política pública asume que lo público-estructural ha resultado de importancia en Colombia, considerando que provee recursos jurídicos para sustentar el acceso de los ciudadanos a los derechos, no obstante la unidad jurídica proporcionada, política pública asume que lo público-estructura está tocado por excesos de fines e ideales que no logran articular la diversidad social en la unidad estatal y, en efecto, la política pública escapa a la formalidad extrema de lo público-estructural.

La segunda tipología de lo público está relacionada con lo público-institucional en la que el eje determinante de sus contenidos y acciones es el sector público que simultáneamente alimenta el gobierno institucional y la estructura territorial del Estado. Así pues, la política pública reconoce aciertos en lo público-institucional, ya que los programas gubernamentales, los planes de desarrollo y la burocracia pública intentan aplicar en ámbitos críticos de la sociedad. Sin embargo, lo públicoinstitucional desata estrategias privadas sobre $\mathrm{e}$ cesolución de problemáticas críticas en el orden municipal y local, situación que obliga distancias con la política pública, gracias a que ésta surge de consensos locales entre actores de diverso origen y estrato; en consecuencia, lo público-institucional y la política pública registran acercamientos parciales, al considerar que el gobierno institucional que aplica fines formales del Estado, no coincide con el carácter plural y local de la política pública.

Los públicos-organizativos constituyen la tercera tipología de interés para la política pública. Éstos se caracterizan por estructurar gobiernos públicos estratégicos, es decir, organizaciones sociales que diseñan y aplican sistemas de decisión sustentados en lógicas culturales y políticas de carácter local y contenidos históricos. Los públicos-organizativos y los gobiernos públicos estratégicos son co-relatos de sociedades estructuradas localmente en las que se diluye la dualidad urbano-rural, considerando que los actores sociales se articulan en organizaciones que mezclan indiscriminadamente estratos económicos, cosmovisiones educativas y familiares, informalidad territorial y estilos de decisión política.

En este marco, lo público surge de contrastes intereses de actores instituyentes que asumen la política pública como el sistema de decisiones que permite legitimar historias locales y problemáticas territoriales, con el propósito de generar campos de consenso entre la informalidad social y la institucionalidad municipal. En efecto, la política pública reconoce en los públicos-organizativos escenas $y$ escenarios en los que se configuran hechos de interés público y local, relacionados con actores sociales legitimados por su capacidad de participar en el juego social, en la perspectiva de diseñar y aplicar técnicas de gobierno público-estratégico.
POLITICAS PÚBLICAS Y SECTORES LOCALES DE INTERÉS.

Las políticas públicas representan sistemas de decisión que los actores sociales implementan para planificar lo público y para generar gobierno público estratégico en ámbitos territoriales concretos. co estratégico en ámbitos territoriales concretos. de condiciones institucionales y públicas que permitan el ascenso de actores e historias locales a la vida pública, para desbloquear la tensión centro-periferia en el orden municipal, y autorizar consensos locales apropiados para deliberar sobre asuntos y temas estratégicos de la ciudad. Hemos indicado que la política pública está vinculada directamente con públicos-organizativos, lo que imtos factores estructu esta relación para constatar que los actores de los públicos-organizativos activan políticas públicas locales y simultáneamente alimentan sus contenidos y análisis.

Erimer factor estructural de la relación política pública y públicos-organizativos, está relacionado con los sectores locales de interés (S.L.I), éstos son actores localizados estratégicamente en la ciudad que conocen y viven eventos y problemáticas locaque conocen y viven eventos y problemáticas locaes que escapan ala lente instituciona. Son organizaciones sociales que registran problemáticas ambientales, económicas, territoriales, educativas de diverso tamaño e impacto en la ciudad. Ésta se concibe a partir de fragmentos que legitiman su diversidad interna a modo de moiéculas espaciales y públicas convergentes, que se aglutinan en consideración de intereses y ciinámicas ciudadanas con distancias notables hacia la institucionalidad administrativa. En consecuencia, los S.L.I son actores de lo público que se autodeterminan social y públicamente y ponen en escena problemáticas y decisiomente y ponen en escena problem
nes objeto de política pública local.

El segundo factor estructural de la relación política pública y públicos-organizativos está vinculado con pública vúblicos-or terizadas por acuerdos estratégicos de los S.L.I so- bre asuntos de ciudad que entrañan lógicas vecinales, barriales, comunales y zonales. Por lo tanto, TiL son situaciones de interés público construidas directamente por organizaciones sociales para legitimarse ante lo público y para facilitar la capacidad deliberativa de los ciudadanos sobre temas de ciudad, que no sólo están reservadas a la administración pública municipal por cuanto también alteran los ritmos cotidianos de los S.L.I. Son T.L el tratamiento institucional de los desconectados por servicios públicos, los desenlaces de la salud pública en la ciudad, la multiplicación de ONGs de corte comunal, el surgimiento de metrópolis po privado de particulares sobre vías y territorios municipales, poliglotismos, exclusiones y violencias urbanas. Las T. L constituyen vértice de política pública y públicos-organizativos, porque elevan a condición de interés público tivos, porque ele en la lente institucional $y$, consecuentemente, no registran en políticas y programas gubernamentales municipales.

El tercer factor estructural de la relación, política pública y públicos-organizativos, está relacionado con el reconocimiento de organizaciones sociales con el reconocimiento de ostores estratégicos para la consolidación de lo público en la ciudad. En efecto, las O.S constituyen para las políticas públicas el mecanismo de roducción social de lo público y el mecanismo de conversación entre la política y la administración. Las O.S representan para las políticas públicas la plataforma material, jurídica y simbólica apropiada para concretar los fines e impactos de la politica pública. Por tanto, es decisivo para la política publica diferenciar dos tipos de OS, las organizaciones sociales instituyentes y las organizaciones sociales constituyentes. Las primeras están vinculadas con historias vitales y locales que se constituyen en objetos de política pública, y las segundas ven en objetos de poittica pública, y las séíicos que están relacio requieren reconocimiento jurídico para justifica intercambios sociales e institucionales. Las organizaciones sociales instituyentes son aquellas que existen tácitamente en la entraña del barrio, de 
la comuna, y que logran cohesionar socialmente a vecinos con vecinos y a éstos con proyectos iniciativas locales de convivencia $y$ solidaridad local. Las organizaciones sociales constituyentes son aquellas que consiguen personería jurídica para situar en la vida pública de la ciudad temas para e debate relativos a S.L.I.

LA POLÍTICA PÚBLICA: UNA ESTRATEGIA DE IMPLEMENTABILIDAD DE DESARROLLO SOCIAL Y LOCAL.

Los enfoques de política pública están relacionados con la ampliación de los escenarios de lo públi$c o$, en el marco de sociedades que registran estabilidad institucional y expresiones de participación social que requieren fortalecimiento. En efecto, los enfoques de política pública están relacionados con aquellos que se configuran a partir de la participación de recursos económicos procedentes del sector público. Igualmente existen enfoques de política pública, sustentados en apoyo e inversión de recursos internacionales que tienen carácter intersectorial, por cuanto circulan entre programas gubernamentales y ciudadanos. También gramas guberna política pu Te territorial, organizativa y local que se comprometen con el registro y fortalecimiento de dinámicas comunitarias.

En el marco del desarrollo social y local será pertinente incursionar en el tercer enfoque de política nente incursionar en el tercer enfoque de política
pública, considerando que el desarrollo social y local requerirá identificación y caracterización de actores comunitarios que construyan políticas públicas de enfoque territorial, organizativo y local; esto es, políticas públicas que faciliten a las orgaesto es, políticas públicas que faciliten a las orga-
nizaciones sociales locales intervenir en la amplianizaciones sociales locales intervenir en la amplia-
ción de lo público mediante la interacción con políticas gubernamentales y con otras organizaciones sociales orientadas a propósitos similares. En consecuencia, el enfoque de política pública relativo al desarrollo social y local, estará determinado por la capacidad de las organizaciones sociales locales para recorrer los cinco factores que articula la polí- tica pública. Por lo tanto, el desarrollo social y local será producto de la aplicación de políticas públicas que permitirán a los actores sociales locales aplica coherentemente el diseño, la implementación, la gestión, el monitoreo y la evaluación como etapas estratégicas para la actuación directa de las organizaciones sociales locales, en la esfera pública del municipio $y$ en el desarrollo local integral.

La política pública de enfoque territorial, organizativo y local asume que su eje de construcción procede de organizaciones sociales locales dispuestas a intervenir en el diseño de política pública. Es decir, en esta etapa las organizaciones sociales locales construyen problemas que registran dinámicas por resolver en el mediano y largo plazo.

En la etapa de implementación, las organizaciones sociales locales establecen alianzas con diversos actores de la sociedad y el gobierno institucional para seleccionar los recursos adecuados y garantizar la aplicación de la política pública en ámbitos críticos y públicos de la ciudad.

La etapa de gestión está articulada a la introducción de recursos en la política pública y en la movilidad de las organizaciones sociales locales para acompañar la frecuencia y cobertura de la política pública en la ciudad.

El monitoreo es la etapa de la política pública en la que las organizaciones sociales locales, registran compromisos ciudadanos y validación de los programas asociados al desarrollo en términos de constatación del impacto, que tiene la política pública en ámbitos específicos de la ciudad.

La etapa de evaluación de política pública esta orientada a demostrar su eficacia en los ámbitos de su aplicación, asumiendo la eficacia como la integralidad de la política pública que combina estratégicamente recursos técnicos, económicos, gubernamentales $y$ organizativos para ofrecer respuestas eficaces a las organizaciones sociales
les ubicadas estratégicamente en la ciudad.
En síntesis, las etapas indicadas de política pública demuestran que las organizaciones sociales locales deberán interactuar en cinco escenarios que simultáneamente reflejarán la cultura política y la capacidad de gobierno público que tienen frente a situaciones críticas de la ciudad.

Hemos indicado que el enfoque de política pública apropiado para la investigación que desarrollamos, es el relacionado con factores territoriales y locales, considerando que el desarrollo social y loca deberá observarse integral y multisectorialmente es decir, el desarrollo social y local en la ciudad será el resultado de la intervención de diversos actores y factores que aportan recursos participativos, económicos y territoriales para lograr que la ciudadanía alcance escenarios de equidad, y de in clusión. Igualmente hemos afirmado que las organizaciones sociales locales deberán incursionar satisfactoriamente en las cinco etapas de la política pública, por cuanto éstas son el punto de contacto entre las organizaciones sociales, las problemáticas identificadas y la política pública.

Después de observar la intervención de las organizaciones sociales en el desarrollo social y local mediante políticas públicas de nivel local, observaremos que surgen efectos en la esfera pública de la ciudad, localizados en ámbitos territoriales estratégicos, esto es, la capacidad de las organizaciones locales de la ciudad para construir e implementar políticas públicas locales, se traducirá en factores de interés para la investigación: las políticas públicas locales facilitarán la articulación del sector público municipal con la diversidad de sectores y organizaciones sociales de la ciudad. Esto implicará que las cosmovisiones de desarrollo, de participación y de inversión procedentes de diver- sos sectores de la ciudad se combinen para propiciar la ampliación de la esfera pública y los canales de participación social.

Las políticas públicas locales facilitarán el fortalecimiento territorial, el carácter

participativo de la política pública facilitará la concurrencia de diversos actores de la ciudad, lo que permitirá rritorial que en todos los casos invertín de construcción de lo público en la ciudad, esto es, lo público procederá de ámbitos y dinámicas territoriales históricamente ocultos en exclusión y marginalidad.

Las políticas públicas locales facilitarán la articulación de la descentralización y los poderes locales, los lenguajes institucionales en materia de desarrollo municipal se concretarán en la vida pública de la ciudad a partir de la intervención que los sectores locales de interés de la ciudad ejerzan en la transformación de los planes y programas de gobierno en áreas y problemas estratégicos de la ciudad. En consecuencia, los poderes locales actuarán como ciudadanías organizadas que conducen programas gubernamentales hacia la materialización socia en diversos territorios de la ciudad. Las políticas públicas locales facilitarán a las organizaciones sociales de la ciudad la incursión en el lenguaje y la práctica del gobierno público, por cuanto las pocerán parte integral del desarrollo local. La estructura de las políticas públicas locales facilitará a las organizaciones sociales de la ciudad, la incursión en el gobierno público que mediante agendas públicas ampliará los escenarios de desarrollo social y local para Medellín, aspectos que investigación 


\section{BIBLIOGRAFÍA}

AGUILAR, Luis. La implementación de las políticas públicas. México. Miguel Ángel Porrúa. 1996.

BARZELAY, Michael. La Nueva Gestión Pública: un acercamiento a la investigación y al debate de las políticas. México. Fondo de Cultura Económica. 2003.

BOZEMAN, Barry. La Gestión pública: su situación actual. Fondo de Cultura Económica. México. 1998. Primera lectura de la Segunda parte: La teoría de la sabiduría y el carácter del conocimiento en la gestión pública; "Imágenes de la gestión pública". Problemas para la creación, una teoría de la gestión pública”." "Teorías de la gestión pública".

CÁRDENAS SANTAMARÍA, Jorge Hernán; ZAMBRANO CETINA William. Gobernabilidad y Reforma del Estado. Diké. Bogotá. 2000.

CARPIZO, Jorge. México: ¿Sistema Presidencial o Parlamentario? México. Colección Xinantecatl. 1999.

DOMÍNGUEZ, Jorge; SHIFTER, Michael. Construcción de gobernabilidad democrática en América Latina. Bogotá. Fondo de Cultura Económica. 1995.

DROR, Yehezkel. La capacidad de gobernar. México. Fondo de cultura económica. 1994.

GINER, Salvador; SARASA, Sebastián (Editores). Buen Gobierno y Política Social. Barcelona. Ariel. 1997.

GUERRERO OROZCO, Omar. Del Estado Gerencial al Estado Cívico. México. UNAM. Colección Xinantecatl. 1999.

HERRERA BOTERO, Fernando. Medellín 1890-1950. Historias Urbanas y Juegos de Intereses. Medellín. Universidad de Antioquia. 1996

KAPLAN, Marcos. El Estado y la teoría política y constitucional en América Latina. México. Siglo XXI. 1990.

SALAZAR VARGAS, Carlos. Las políticas públicas. Pontificia Universidad Javeriana. Facultad de Ciencias Jurídicas. Colección Profesores № 19, 1999. 2a edición.

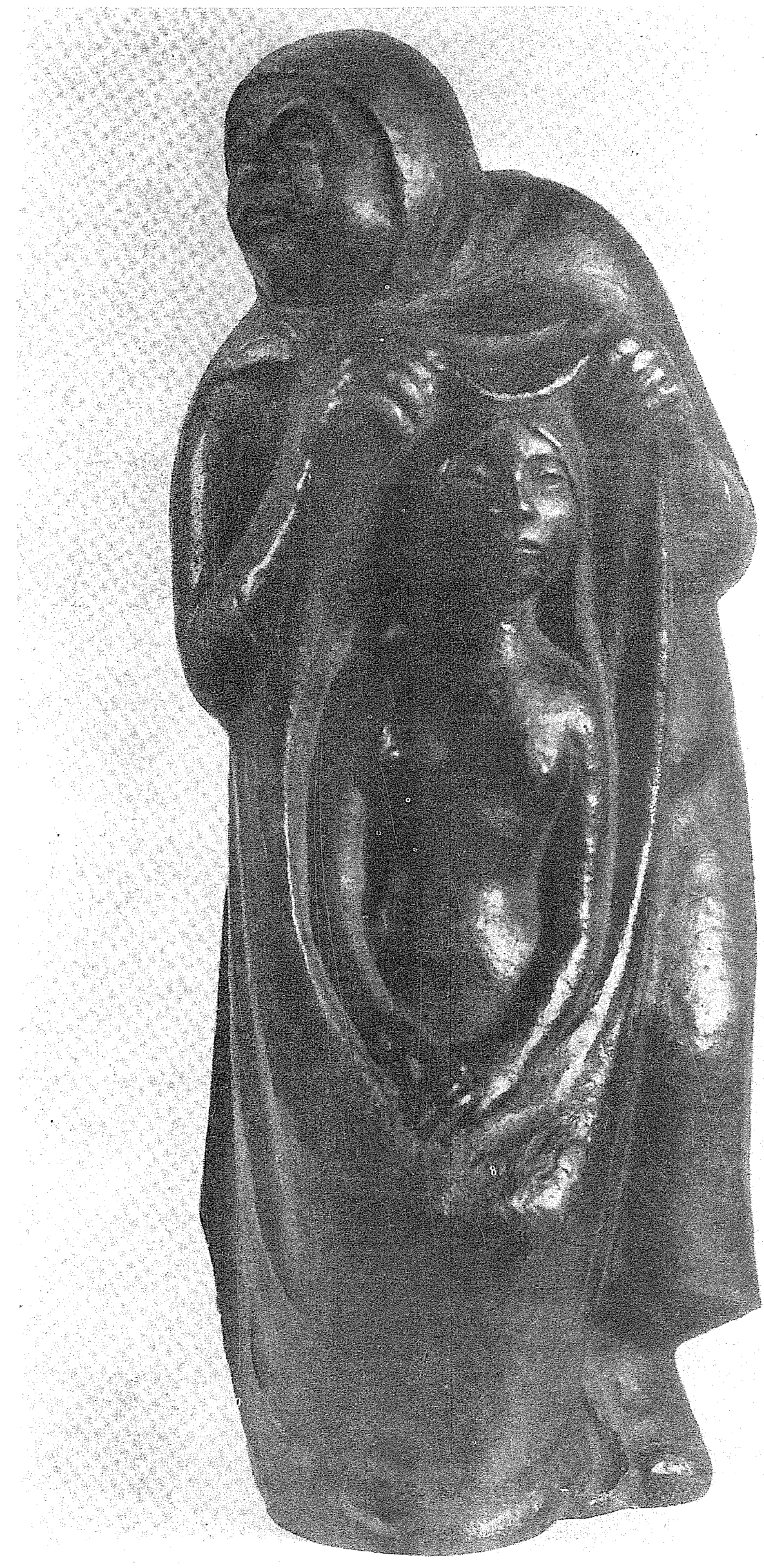

